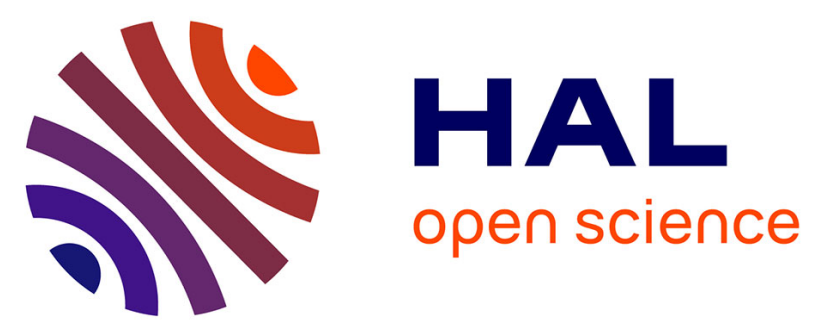

\title{
Adsorption of pharmaceuticals onto activated carbon fiber cloths - Modeling and extrapolation of adsorption isotherms at very low concentrations
}

Hélène Fallou, Nicolas Cimetiere, Sylvain Giraudet, Dominique Wolbert, Pierre Le Cloirec

\section{To cite this version:}

Hélène Fallou, Nicolas Cimetiere, Sylvain Giraudet, Dominique Wolbert, Pierre Le Cloirec. Adsorption of pharmaceuticals onto activated carbon fiber cloths - Modeling and extrapolation of adsorption isotherms at very low concentrations. Journal of Environmental Management, 2016, 166, pp.544-555. 10.1016/j.jenvman.2015.10.056 . hal-01236454

HAL Id: hal-01236454

https://hal-univ-rennes1.archives-ouvertes.fr/hal-01236454

Submitted on 23 May 2016

HAL is a multi-disciplinary open access archive for the deposit and dissemination of scientific research documents, whether they are published or not. The documents may come from teaching and research institutions in France or abroad, or from public or private research centers.
L'archive ouverte pluridisciplinaire HAL, est destinée au dépôt et à la diffusion de documents scientifiques de niveau recherche, publiés ou non, émanant des établissements d'enseignement et de recherche français ou étrangers, des laboratoires publics ou privés. 


\section{Adsorption of pharmaceuticals onto activated carbon fiber cloths}

Modeling and extrapolation of adsorption isotherms at very low concentrations

Hélène Fallou ${ }^{\mathrm{a}}$, Nicolas Cimetière ${ }^{\mathrm{a}}$, Sylvain Giraudet ${ }^{\mathrm{a}^{*}}$, Dominique Wolbert ${ }^{\mathrm{a}}$,

Pierre Le Cloirec ${ }^{a}$

a Ecole Nationale Supérieure de Chimie de Rennes, CNRS, UMR 6226,11 Allée de Beaulieu, CS 50837, 35708 Rennes Cedex 7, France

helene.fallou@ensc-rennes.fr

nicolas.cimetiere@ensc-rennes.fr

sylvain.giraudet@ensc-rennes.fr

dominique.wolbert@ensc-rennes.fr

pierre.le-cloirec@ensc-rennes.fr

\footnotetext{
* Corresponding author

E-mail : sylvain.giraudet@ensc-rennes.fr

Tel. (+33)223238015

Fax : (+33)223238120
} 


\section{Abstract}

Activated carbon fiber cloths (ACFC) have shown promising results when applied to water treatment, especially for removing organic micropollutants such as pharmaceutical compounds. Nevertheless, further investigations are required, especially considering trace concentrations, which are found in current water treatment. Until now, most studies have been carried out at relatively high concentrations (mg. $\left.\mathrm{L}^{-1}\right)$, since the experimental and analytical methodologies are more difficult and more expensive when dealing with lower concentrations $\left(\mathrm{ng} \cdot \mathrm{L}^{-1}\right)$. Therefore, the objective of this study was to validate an extrapolation procedure from high to low concentrations, for four compounds (Carbamazepine, Diclofenac, Caffeine and Acetaminophen). For this purpose, the reliability of the usual adsorption isotherm models, when extrapolated from high (mg. $\left.\mathrm{L}^{-1}\right)$ to low concentrations (ng. $\mathrm{L}^{-1}$ ), was assessed as well as the influence of numerous error functions. Some isotherm models (Freundlich, Toth) and error functions (RSS, ARE) show weaknesses to be used as an adsorption isotherms at low concentrations. However, from these results, the pairing of the Langmuir-Freundlich isotherm model with Marquardt's percent standard of deviation was evidenced as the best combination model, enabling the extrapolation of adsorption capacities by orders of magnitude.

\section{Keywords}

Extrapolation; adsorption capacities; trace concentrations; activated carbon fiber cloths; micropollutants 


\section{Introduction}

The contamination of aquatic systems by pharmaceutical residues is widely reported and constitutes a growing concern and risk for the environment and human health (Das et al., 2014; Gamarra et al., 2015; Huerta-Fontela et al., 2011). For instance, Loos et al., (2009) detected diclofenac in 83 \% of their samples in European rivers. The maximum concentration was $11 \mathrm{ng} \cdot \mathrm{L}^{-1}$ (de Jesus Gaffney et al., 2015). Likewise, carbamazepine and acetaminophen were identified and quantified at concentrations of 200 ng. $\mathrm{L}^{-1}$ in surface waters (Segura et al., 2011). Exposure to environmentally concentrations of pharmaceutical residues (Carbamazepine, Diclofenac and Acetaminophen) could alter biomarkers and biochemical processes of C. fluminea and duckweed plants (Chen et al., 2014; Kummerová et al., 2015). However, risks for human health were considered negligible by Webb et al., (2003).

Adsorption processes are recognized among the most efficient, promising and widespread water treatments for the removal of pharmaceuticals (Foo and Hameed, 2009). In practice, granular activated carbon (GAC) and/or powdered activated carbon (PAC) are used to eliminate organic pollutants. According to (Rigobello et al., 2013; Sotelo et al., 2014), the adsorption capacities of diclofenac onto granular activated carbon are about $230 \mathrm{mg} \cdot \mathrm{g}^{-1}$ for a residual aqueous concentration of $40 \mathrm{mg} \cdot \mathrm{L}^{-1}$. For carbamazepine, Cai and Larese-Casanova (2014) found capacities of $200 \mathrm{mg} \cdot \mathrm{g}^{-1}$ onto granular activated carbon for a concentration of $0,5 \mathrm{mg} \cdot \mathrm{L}^{-1}$. For a residual concentration of $500 \mathrm{ng} \cdot \mathrm{L}^{-1}$, (Yu et al., 2008) found capacities of $1 \mathrm{mg} \cdot \mathrm{g}^{-1}$. More recently, activated carbon fiber cloths (ACFC) have also been studied for water treatment (Faur-Brasquet et al., 2002). The advantages of such textiles are their high specific surface areas, predominantly microporous texture and large adsorption capacities (Ayranci and Hoda, 2005). Therefore, ACFC were more efficient in terms of adsorption rate and selectivity than granular activated carbon for the removal of phenols (Dabrowski et al., 2005). However, to our knowledge, few studies have dealt with the adsorption of pharmaceutical residues onto ACFC (Ayranci and Duman, 2006; Bayram and Ayranci, 2012; Guedidi et al., 2014). 
The design of the adsorption process is generally based on the equilibrium data for the particular system: adsorbent vs. adsorbate. Thus, relevant and accurate models for the sorption equilibrium are critical to predict the performances of the treatment. Adsorption isotherms (relationship between the amount adsorbed at equilibrium and the residual aqueous concentration for a given temperature) are usually reported for a narrow range of concentrations. Moreover, high aqueous concentrations (about mg. $\mathrm{L}^{-1}$ ) (Brasquet et al., 1996) of pollutants are commonly considered since trace concentrations are hardly achievable unless a complex and costly analytical strategy is carried out. The question is whether the adsorption capacities obtained at high concentrations can be easily transposed to realistic trace conditions. As mentioned above, in aquatic compartments, the concentrations of pharmaceutical residues are very low (in the ng. $\mathrm{L}^{-1}$ range) and the determination of adsorption isotherms at such environmental concentrations is difficult, requiring powerful analytical tools such as liquid chromatography coupled to mass spectrometry and time-consuming sample preparation (solid phase extraction).

The accuracy of the extrapolation is greatly dependent on the isotherm model considered as well as the adjustment procedure used for the optimization of the isotherm parameters. In the literature, numerous isotherm models are available, starting from the Freundlich and Langmuir models, which have been widely used and validated to describe equilibrium relationships between various adsorbents and adsorbates (Ho, 2004; Nam et al., 2014; Sotelo et al., 2014; Yu et al., 2008). Nam et al. (2014) have shown a better fit of adsorption onto granular activated carbon with the linear form of the Langmuir model, compared to the Freundlich model, for acetaminophen adsorption. These authors used concentrations of pollutants between 20 and $500 \mathrm{ng} \cdot \mathrm{L}^{-1}$, with a mass of granular activated carbon of $1 \mathrm{mg} \cdot \mathrm{L}^{-1}$. Regarding diclofenac, (Nam et al., 2014) have shown a better fit with the Freundlich model while, for carbamazepine, (Yu et al., 2008) have shown better results with the Freundlich model, for an equilibrium concentration of $10-800 \mathrm{ng} \cdot \mathrm{L}^{-1}$. Over the years, a wide variety of equilibrium isotherm models have been developed while considering various assumptions 
(heterogeneity of the surface energy, multilayer adsorption, etc.). These isotherm models can be classified as two-parameter (Langmuir, Freundlich, Temkin, Elovich, Dubinin-Radushkevich) or threeparameter models (Redlich-Peterson, Toth, Langmuir-Freundlich, Sips, Radke-Prausnitz). (Limousin et al., 2007; Rouquerol et al., 1999; Ruthven, 1984; Worch, 2012).

In combination with the selection of the relevant model, various options are possible to determine the model parameters: linearization of the equations with a simple least-square regression or a nonlinear regression method. This latter approach has generally been preferred since it provides the most accurate description of experimental data (Foo and Hameed, 2010). Moreover, some models cannot be linearized and the determination of parameters is necessarily based on minimizing an error function, which corresponds to the deviation between the experimental data and the predicted value from the model. The optimized parameters for the isotherm model thus strongly depend on the selected error function. It should be noted that the choice of the error function influences the accuracy of the modeled data, since this function promotes a better fit of isotherms at low or high concentration with different weights for the experimental data.

Recent studies have compared several error functions in combination with the usual isotherm models (Allen et al., 2003; Chan et al., 2012; Foo and Hameed, 2010). Normally, error functions are used to minimize or maximize the error distribution between the experimental equilibrium data and the predicted isotherms, according to the definition of the error function. Although the method of least squares is one of the most widely used techniques with the maximum coefficient of determination, $\mathrm{r}^{2}$, some studies have pointed out that other error functions are more relevant, such as the hybrid fractional error function (HYBRID), Marquardt's percent standard of deviation (MPSD), the average relative error (ARE), the sum of the absolute errors (EABS) etc. According to Chan et al. (2012), the hybrid error function provided the best overall results. For this study, the Sips model performed the best prediction only if the model was adjusted using the hybrid method with the experimental data. 
Most investigations have been carried out for the adsorption of organic compounds at high concentrations (at the $\mathrm{mg}^{-\mathrm{L}^{-1}}$ scale) (Sotelo et al., 2014). Only recently, research programs have focused on the modeling of adsorption isotherms at lower concentrations ( $\mu \mathrm{g} \cdot \mathrm{L}^{-1}$ or less) with the development of analytical tools (Al Mardini and Legube, 2010; Matsui et al., 2003). This trend is more consistent with the emerging pollutants encountered in the environment and should be generalized to achieve a better understanding of the adsorption process used for the production of drinking water. However, at trace concentrations, experimental results are more difficult and more expensive to obtain. In order to avoid this problem, the extrapolation of the isotherm model from high to low concentrations would be an interesting option. In fact, if the model is fitted at high concentrations, the prediction outside the range of measurements (to trace contents) could give relevant results. As previously mentioned, the selection of the isotherm model and the error function plays a key role in predicting adsorption capacities.

This study focused on the relevance and reliability of the extrapolation of adsorption isotherms from high to low concentrations, with the aim of evaluating the ability of numerous isotherm model/error function pairs to achieve this change of scale. For this purpose, three emerging pollutants were chosen and their isotherms of adsorption were determined for one ACFC. Two sets of experiments were carried out at low and high concentrations. Then, the combinations between 13 models and 8 error functions were evaluated.

\section{Materials and methods}

\subsection{Materials}

\subsubsection{Organic compounds}

The targeted compounds - acetaminophen, carbamazepine and diclofenac - were all purchased from Sigma-Aldrich (purity $>98 \%$ ). The physicochemical properties and molecular structures of the 
compounds are listed in Table 1 . Stock solutions $\left(10 \mathrm{mg} \cdot \mathrm{L}^{-1}\right)$ were prepared by dissolving the commercial standard in ultrapure water (UPW) provided by an ElgaPureLab System (18.2 M $2 . \mathrm{cm})$. Two sets of experiments were carried out. The first was conducted at high concentrations of pollutant $\left(0.1-20 \mathrm{mg} \cdot \mathrm{L}^{-1}\right)$. The second set was achieved at low concentrations $\left(0.1-2 \mu \mathrm{g} \cdot \mathrm{L}^{-1}\right)$, which is the range closer to the levels observed in surface waters (Petrie et al., 2014).

For the high range of concentrations, analyses were performed by Ultra Performance Liquid Chromatography (UPLC) using a Waters ACQUITY H-class system (Waters Assoc., Milford, MA) equipped with a photodiode array detector (PDA). Detection was carried out at 243, 272, 276 and $280 \mathrm{~nm}$ with a PDA e $\lambda$ detector (Waters) for acetaminophen, diclofenac and carbamazepine, respectively. $5 \mu \mathrm{L}$ of sample was injected onto a BEH C18 column (100 x $2.1 \mathrm{~mm} \times 1.7 \mu \mathrm{m}$, Waters) thermostated at $35{ }^{\circ} \mathrm{C}$. The binary gradient consisted of a mixture of acetonitrile as mobile phase $\mathrm{A}$, and acetonitrile/water/formic acid (10:90:0.1, v/v/v) as mobile phase B. The separation was initiated at a constant flow of $0.4 \mathrm{ml} / \mathrm{min}$ with $90 \%$ B for $1 \mathrm{~min}$, followed by a decrease in B to $10 \%$ within 7 min. This composition was then maintained for $10 \mathrm{~min}$ and returned to the initial composition.

For the low range of concentrations, analyses of the selected compounds were performed using UPLC with an Acquity system (Waters) coupled with a tandem mass spectrometer (Quattro Premier, Micromass). The chromatographic system included a 2777 autosampler (Waters) equipped for dual on-line solid phase extraction (on-line SPE) with HLB cartridges. $5 \mathrm{~mL}$ of sample was loaded onto the HLB column using a large volume injection loop and a quaternary solvent pump (QSM - Waters). After the loading and cleaning steps, HLB cartridges were connected to the analytical hydraulic circuit. Chromatographic conditions were similar to those described previously.

Mass spectrometry was used with an electrospray ionization source in positive mode with a capillary voltage of $3 \mathrm{kV}$ and nitrogen as the nebulizer and drying gas. The cone gas flow and the desolvation gas flow were set at $50 \mathrm{~L} \mathrm{~h}^{-1}$ and $750 \mathrm{~L} \mathrm{~h}^{-1}$, respectively. The source temperature and desolvation gas 
temperature were $120{ }^{\circ} \mathrm{C}$ and $350^{\circ} \mathrm{C}$, respectively. The multiple reaction monitoring (MRM) mode was used for the quantification of all compounds. Retention time, MRM transitions, cone voltage and collision cell energy are summarized in Table 1.

Table 1 : Properties of pharmaceutical residues used in adsorption procedures

\begin{tabular}{|c|c|c|c|}
\hline Compound & Acetaminophen & Carbamazepine & Diclofenac \\
\hline $\mathrm{N}^{\circ} \mathrm{CAS}$ & $103-90-2$ & 298-46-4 & $15307-79-6$ \\
\hline $\mathrm{MW}\left(\mathrm{g} \cdot \mathrm{mol}^{-1}\right)$ & 151.16 & 236.27 & 318.13 \\
\hline log Kow & 0.46 & 2.45 & 4.51 \\
\hline pKa & 9.5 & 14 & 4.15 \\
\hline Solubility (g. $\mathrm{L}^{-1}$ ) & 14.9 & 0.02 & 50.0 \\
\hline Size $(A)$ & $7 * 5 * 2$ & $10 * 8 * 5$ & $10 * 8 * 1$ \\
\hline Cone Voltage (V) & 25 & 28 & 22 \\
\hline Collision energy (eV) & 19 & 19 & 25 \\
\hline Transition & $152>110$ & $237.1>194$ & $296.1>250$ \\
\hline Retention time ( $\mathrm{min}$ ) & 1.49 & 3.61 & 4.73 \\
\hline
\end{tabular}

\subsubsection{Adsorbent}

The ACFC was supplied by Dacarb (Asnières-sur-Seine, France). It was soaked as received in ultrapure water to remove any dissolved contaminants and/or fine particles and then dried at $120^{\circ} \mathrm{C}$ prior to the experiment. The physical and chemical characteristics of the ACFC are given in Table 2 . The physisorption of nitrogen at $77 \mathrm{~K}$ (Autosorb, Quantachrome Instruments) was used to determine the specific surface area (multi-point BET method in the range of relative pressures 0.01 to 0.1 ), the total pore volume (relative pressure of 0.995$)$, the micropore volume and the average pore size (Quenched Solid State Functional Theory, QSDFT) (Condon, 2006; Rouquerol et al., 1994). In addition, the Boehm titration method was used to quantify the functional surface groups (Boehm, 1994). 
The ACFC possesses a highly microporous texture (over $90 \%$ of the total pore volume) and few functional groups in comparison to common granular activated carbons (Lopez-Ramon et al., 1999). This specificity was confirmed by the residual $\mathrm{pH}$ (measured after $24 \mathrm{~h}$ in ultrapure water), which was close to neutrality and in agreement with the balance between acidic and basic groups. This information is summarized in Table 2.

Table 2 : Physical and chemical properties of the ACFC

\begin{tabular}{lc}
\hline \multicolumn{1}{c}{ Textural properties from $\mathrm{N}_{2}$ adsorption at $77 \mathrm{~K}$} \\
\hline Specific surface area $\left(\mathrm{m}^{2} \cdot \mathrm{g}^{-1}\right)$ & 1615 \\
Total pore volume $\left(\mathrm{cm}^{3} \cdot \mathrm{g}^{-1}\right)$ & 1.02 \\
Micropore volume $(\mathrm{QSDFT})\left(\mathrm{cm}^{3} \cdot \mathrm{g}^{-1}\right)$ & 0.92 \\
Micropore size (QSDFT) $(\mathrm{nm})$ & $<0.48$ \\
\hline \multicolumn{1}{c}{ Chemical surface properties from Boehm titration } \\
\hline Residual $\mathrm{pH}$ & 6.14 \\
Basic functions $\left(\mu \mathrm{eq} \cdot \mathrm{L}^{-1}\right)$ & 286 \\
Carboxylic acid functions $\left(\mu \mathrm{eq} \cdot \mathrm{L}^{-1}\right)$ & 12 \\
Lactone functions $\left(\mu \mathrm{eq} \cdot \mathrm{L}^{-1}\right)$ & 87 \\
Phenolic functions $\left(\mu \mathrm{eq} \cdot \mathrm{L}^{-1}\right)$ & 377 \\
\hline
\end{tabular}

\subsection{Adsorption isotherm curves}

Kinetics and adsorption isotherms were performed for single components and multi-components in UPW. For the set of experiments at high concentration, each reactor contained $1 \mathrm{~L}$ of the aqueous solution with the single targeted compound. Initial concentrations $\left(C_{0}\right)$ ranged from $0.1 \mathrm{mg} \cdot \mathrm{L}^{-1}$ to 20 mg. $\mathrm{L}^{-1}$. On the other hand, $10 \mathrm{~L}$ reactors were used for the second set of experiments and the concentrations ranged from $100 \mathrm{ng} \cdot \mathrm{L}^{-1}$ to $2 \mu \mathrm{g} \cdot \mathrm{L}^{-1}$ (multi-components). Preliminary experiments demonstrated that inter-component adsorption competition was not significant if the initial concentration was lower than $10 \mu \mathrm{g} \cdot \mathrm{L}^{-1}$.

The $\mathrm{pH}$ was maintained at 7.5 using hydrogen carbonate buffer and did not vary more than $0.1 \mathrm{pH}$ unit between the initial and final time of the experiment. A constant mass of ACFC ( $20 \mathrm{mg} \pm 0.2)$ was then incorporated and the reactors were tightly sealed and shaken at $400 \mathrm{rpm}$. A constant temperature of $25^{\circ} \mathrm{C}$ was achieved using a thermostatic bath. Preliminary kinetic data indicated that, for all cases, the adsorption equilibrium was reached within 10 days. After equilibration, the 
supernatants were filtered using a $0.2 \mu \mathrm{m}$ GHP Acrodisc filter prior to analysis by SPE-UPLC/ MS-MS in order to determine the residual concentration $\left(C_{e}\right)$ and adsorption capacities $\left(Q_{e}\right)$ according to the mass balance.

\subsection{Isotherm models}

As previously mentioned, numerous models have been formulated to describe adsorption equilibria, considering various assumptions to represent the adsorption phenomenon. Table 3 presents the most common equations for adsorption in the aqueous phase. An ideal model should have four properties: it must be effective, comprehensive, realistic and predictive (Worch, 2012). The choice of the isotherm model is important to understand the state of the adsorbed phase, the interactions between the adsorbent surface and the adsorbed molecules, and the interactions between the adsorbed molecules.

The Freundlich model is widely used for organic pollutants. However, this isotherm model has no limitation to the adsorption capacity at the highest liquid-phase concentrations. On the contrary, the Langmuir isotherm model follows a Henry-type equation at low concentrations and a saturation limit at high concentrations. According to this model, adsorption takes place at specific homogeneous sites within the adsorbent, and once a molecule occupies a site, no further adsorption can take place onto this site. The Langmuir equation can be expressed in its general form (L) or with linearized relationships (L1-L5). Elovich's model is based on kinetic development and supposes a multi-layer adsorption. Three-parameter models have been derived from the Langmuir and Freundlich models. The Sips equation is a combination of these two isotherm equations. At low concentrations, it effectively reduces to a Freundlich isotherm and thus does not follow Henry's law. At high concentrations, the Sips model predicts a monolayer sorption capacity, which is a characteristic similar to the Langmuir isotherm (Foo and Hameed, 2010). The Toth equation is another empirical model developed to improve Langmuir isotherm fittings and useful for describing heterogeneous adsorption isotherm systems, which satisfy both the low- and high-end boundary of the concentration. Adsorption sites are considered to possess low energies. 
Table 3. Adsorption models and error functions for the adjustment of the isotherm adsorption model

\begin{tabular}{|c|c|c|c|}
\hline Isotherm & Number of parameters & Mathematical expression & Reference \\
\hline Freundlich (F) & 2 & $\mathrm{q}_{\mathrm{e}}=\mathrm{K}_{\mathrm{F}} \cdot \mathrm{C}_{\mathrm{e}}^{\mathrm{n}}$ & (Freundlich, 1906) \\
\hline Langmuir (L) & 2 & $\underline{\mathrm{q}_{\mathrm{e}}}=\frac{\mathrm{bC}_{\mathrm{e}}}{1}$ & (Langmuir, 1915) \\
\hline Langmuir 1 (L1) & 2 & $\begin{array}{l}\frac{1}{q_{m}}=\frac{1}{q_{e}} \frac{1}{C_{e}} \frac{1}{q_{m} b}+\frac{1}{q_{m}}\end{array}$ & (Langmuir, 1915) \\
\hline Langmuir 2 (L2) & 2 & $\frac{C_{e}}{q_{e}}=C_{e} \frac{1}{q_{m}}+\frac{1}{q_{m} b}$ & (Langmuir, 1915) \\
\hline Langmuir 3 (L3) & 2 & $\mathrm{q}_{\mathrm{e}}=-\frac{1}{\mathrm{~b}} \frac{\mathrm{q}_{\mathrm{e}}}{\mathrm{C}_{\mathrm{e}}}+\mathrm{q}_{\mathrm{m}}$ & (Langmuir, 1915) \\
\hline Langmuir 4 (L4) & 2 & $\frac{q_{e}}{C_{e}}=-b q_{e}+b q_{m}$ & (Langmuir, 1915) \\
\hline Langmuir 5 (L5) & 2 & $\frac{1}{\mathrm{C}_{\mathrm{e}}}=\mathrm{bq}_{\mathrm{m}} \frac{1}{\mathrm{q}_{\mathrm{e}}}-b$ & (Langmuir, 1915) \\
\hline Elovich (Ev) & 2 & $\frac{q_{e}}{q_{m}}=b_{e} C_{e} \exp -\left(\frac{q_{e}}{q_{m}}\right)$ & (Elovich and Larinov, 1962) \\
\hline $\begin{array}{l}\text { Langmuir-Freundlich } \\
\text { (L-F) }\end{array}$ & 3 & $\frac{\mathrm{q}_{\mathrm{e}}}{\mathrm{q}_{\mathrm{m}}}=\frac{\left(\mathrm{bC}_{\mathrm{e}}\right)^{\mathrm{n}}}{1+\left(\mathrm{bC}_{\mathrm{e}}\right)^{\mathrm{n}}}$ & (Sips, 1948) \\
\hline Sips (S) & 3 & $\frac{\mathrm{q}_{\mathrm{e}}}{\mathrm{q}_{\mathrm{m}}}=\frac{\mathrm{bC}_{\mathrm{e}} \mathrm{n}^{\mathrm{n}}}{1+\mathrm{bC}_{\mathrm{e}}{ }^{\mathrm{n}}}$ & (Sips, 1948) \\
\hline $\begin{array}{l}\text { Linearized Langmuir- } \\
\text { Freundlich (LLF) }\end{array}$ & 3 & $=\frac{\mathrm{q}_{\mathrm{m}}}{\frac{1}{\mathrm{bC}_{\mathrm{e}}{ }^{\mathrm{n}}}+\frac{1}{\mathrm{~b}}}$ & (Limousin et al., 2007) \\
\hline Tóth & 3 & $\underline{\mathrm{q}_{\mathrm{e}}}=\underline{\mathrm{bC}_{\mathrm{e}}}$ & (Toth, 1971) \\
\hline & & $\mathrm{q}_{\mathrm{m}}-\left(1+\left(\mathrm{bC}_{\mathrm{e}}\right)^{\mathrm{n}}\right)^{1 / \mathrm{n}}$ & \\
\hline Error function name & & Mathematical expression & Example of use \\
\hline $\begin{array}{l}\text { Sum of the squared } \\
\text { residual }\end{array}$ & RSS & $\sum_{\substack{\mathrm{i}=1 \\
\mathrm{n}}}^{\mathrm{n}}\left(\mathrm{q}_{\mathrm{e}}-\hat{\mathrm{q}}_{\mathrm{e}}\right)_{\mathrm{i}}^{2}$ & (Kumar, 2006) \\
\hline Relative error & $E$ & $\mathrm{E}=\frac{1}{\mathrm{n}} \sum_{\mathrm{i}=1} \frac{\mathrm{q}_{\mathrm{e}, \mathrm{i} \bmod ^{-} \mathrm{q}_{\mathrm{e}, \mathrm{i}} \exp }}{\mathrm{q}_{\mathrm{e}, \mathrm{i}} \exp }$ & \\
\hline $\begin{array}{l}\text { Average of absolute } \\
\text { error }\end{array}$ & EABS & $\frac{1}{n} \sum_{i=1}^{n}\left|q_{e}-q_{e, a v g}\right|_{i}$ & (Ng et al., 2003) \\
\hline Average relative error & ARE & $\frac{1}{n} \sum_{i=1}\left(\frac{q_{e}-q}{q_{e}}\right)_{i}$ & (Kapoor and Yang, 1989) \\
\hline $\begin{array}{l}\text { Standard deviation of } \\
\text { relative errors }\end{array}$ & $\mathrm{S}_{\mathrm{RE}}$ & $\sum_{\mathrm{i}=1}^{\mathrm{n}}\left(\left(\frac{\mathrm{q}_{\mathrm{e}}-\hat{\mathrm{q}}}{\mathrm{q}_{\mathrm{e}}}\right)_{\mathrm{i}}-\mathrm{ARE}\right)_{\mathrm{i}}^{2}$ & (Boulinguiez et al., 2008) \\
\hline Chi-square & $\chi^{2}$ & $\sum_{i=1}^{n}\left(\frac{q_{e}-q_{e, a v g}}{q_{e}}\right)_{i}^{2}$ & (Boulinguiez et al., 2008) \\
\hline $\begin{array}{l}\text { Marquardt's percent } \\
\text { standard deviation }\end{array}$ & MPSD & $\sqrt{\frac{1}{n-p} \sum_{i=1}^{n}\left(\frac{q_{e}-q_{e, a v g}}{q_{e}}\right)_{i}^{2}}$ & (Marquardt, 1963) \\
\hline Hybrid function & Hybrid & $\frac{1}{n-p} \sum_{i=1}^{n}\left(\frac{q_{e}-q_{e, a v g}}{q_{e}}\right)_{i}^{2}$ & (Ng et al., 2003) \\
\hline
\end{tabular}




\subsection{Error functions}

The parameters of each isotherm model then have to be adjusted to fit the experimental data (Limousin et al., 2007). Initially, the values of each parameter were guessed and predicted isotherm data $q_{e, a v g}$ were computed. Assessment of the goodness-of-fit was then discussed in terms of various error functions. Searching for the best fitted adsorption isotherm using the method of least squares (RSS) is the most widely used technique to predict the optimum isotherm. However, at higher concentration ranges, squares of errors tend to increase, so that this range of concentration has more weight on the fitting procedure than the lower values of concentration/capacities (Foo and Hameed, 2010). As a consequence, for extrapolation towards trace concentrations, the RSS error function is probably inappropriate and the prediction of low values of the isotherm from data obtained at high concentration requires alternative error functions. The hybrid function was developed to improve the RSS fit at low concentrations. Average relative error (ARE) attempts to minimize the fractional error distribution over the entire concentration range. The sum of absolute errors (EABS) approach provides a better fit compared to the RSS model although this function also favors the highest concentrations. The coefficient of determination $\left(r^{2}\right)$ represents the percentage of variability in the dependent variable. Standard deviations of relative errors ( $\mathrm{s}_{\mathrm{RE}}$ ) are individually determined to evaluate the overall correlation and the dispersion of its relative errors (Foo and Hameed, 2010). Marquardt's percent standard deviation (MPSD) is similar to a geometric mean error distribution modified according to the number of degrees of freedom of the system. These models are presented in Table 3.

Previously, linear regressions were used to fit isotherms. This procedure was easily applied to many experimental data and the equations were quite simple (Ayoob and Gupta, 2008). However, more recently, many researchers have combined isotherm models with different error functions to show the applicability of linear or non-linear isotherm models to describe the adsorption mechanism. Table 4 summarizes, for adsorption onto activated carbon only, the different combinations of isotherm model/error function used to depict the adsorption of organic and inorganic pollutants. 
Table 4. Some uses of isotherm adsorption models with different error functions

\begin{tabular}{|c|c|c|c|c|c|}
\hline $\begin{array}{l}\text { Type of activated } \\
\text { carbon }\end{array}$ & Adsorbate & Isotherm models & Error functions & $\begin{array}{l}\text { Linear/non } \\
\text {-linear }\end{array}$ & Reference \\
\hline Activated carbon & $\begin{array}{l}\text { Tetrahydrothi(o) } \\
\text { phene }\end{array}$ & Langmuir & $\begin{array}{c}r^{2}, \text { EABS, RSS, } \\
\text { ARE, } S_{R E}, \text { Hybrid }\end{array}$ & Non-linear & $\begin{array}{l}\text { (Boulinguiez } \\
\text { et al., 2008) }\end{array}$ \\
\hline Activated carbon & Methylene blue & $\begin{array}{c}\text { Freundlich, } \\
\text { Langmuir, Redlich- } \\
\text { Peterson }\end{array}$ & $\begin{array}{c}r^{2}, \text { ARE, Hybrid, } \\
\text { MPSD, EABS }\end{array}$ & Non-linear & $\begin{array}{l}\text { (Kumar et } \\
\text { al., 2008a) }\end{array}$ \\
\hline Activated carbon & Basic red 9 & $\begin{array}{c}\text { Freundlich, } \\
\text { Langmuir, Redlich- } \\
\text { Peterson }\end{array}$ & $\begin{array}{l}r^{2}, E A B S, \text { Hybrid, } \\
\text { ARE, SAE, MPSD }\end{array}$ & Non-linear & $\begin{array}{l}\text { (Kumar et } \\
\text { al., 2008b) }\end{array}$ \\
\hline Activated carbon & Basic blue 9 dye & $\begin{array}{c}\text { Freundlich, } \\
\text { Langmuir, Redlich- } \\
\text { Peterson }\end{array}$ & $r^{2}, \chi^{2}$ & Non-linear & $\begin{array}{l}\text { (Jumasiah et } \\
\text { al., 2005) }\end{array}$ \\
\hline Activated carbon & Acid dyes & $\begin{array}{c}\text { Freundlich, } \\
\text { Langmuir, Sips, } \\
\text { Redlich-Peterson }\end{array}$ & $\begin{array}{c}\text { Hybrid, MPSD, } \\
\text { ARE, EABS }\end{array}$ & $\begin{array}{l}\text { Linear and } \\
\text { non-linear }\end{array}$ & $\begin{array}{c}\text { (Chan et al., } \\
\text { 2012) }\end{array}$ \\
\hline
\end{tabular}

\subsection{Adjustment procedure, validation and extrapolation}

Optimization was achieved, using the Microsoft Excel solver, for all the combinations of isotherm models with error functions (Table 3). However, the accuracy of the prediction was difficult to compare since the values for the error functions could not be compared with each other. Therefore, in order to compare the ability of the "isotherm model/error function" couples to describe and predict experimental data, the sum of relative error (E) was used as the comparative variable. The methodology is illustrated in Figure 1. First, the parameters of each isotherm model were optimized for the full range of concentrations (FR) in accordance with the error functions. These parameters were then used to determine two average relative errors $(E)$. $E_{F R}$ was related to the average relative error for all experimental data, whereas $E_{F R-L C}$ corresponded to the error of the model for the set of low concentrations based on the FR optimization of parameters. On the other hand, the isotherm parameters were adjusted to the set of high concentrations and the corresponding $E_{\mathrm{HC}}$ was calculated. Finally, the accuracy of the extrapolation was determined from $\mathrm{E}_{\mathrm{HC}-\mathrm{LC}}$, which was the average relative error for the low range of concentrations with parameters determined at high concentrations (Figure 1) (Assoumani et al., 2009). 


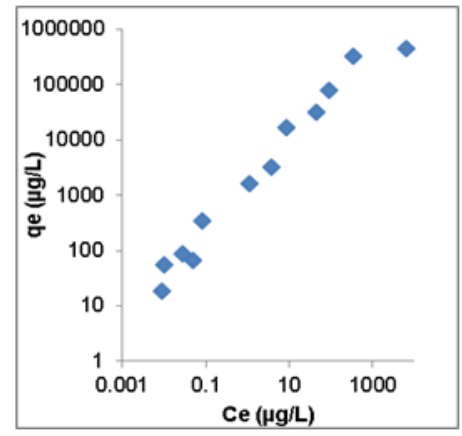

Full-range experimental data (FR)
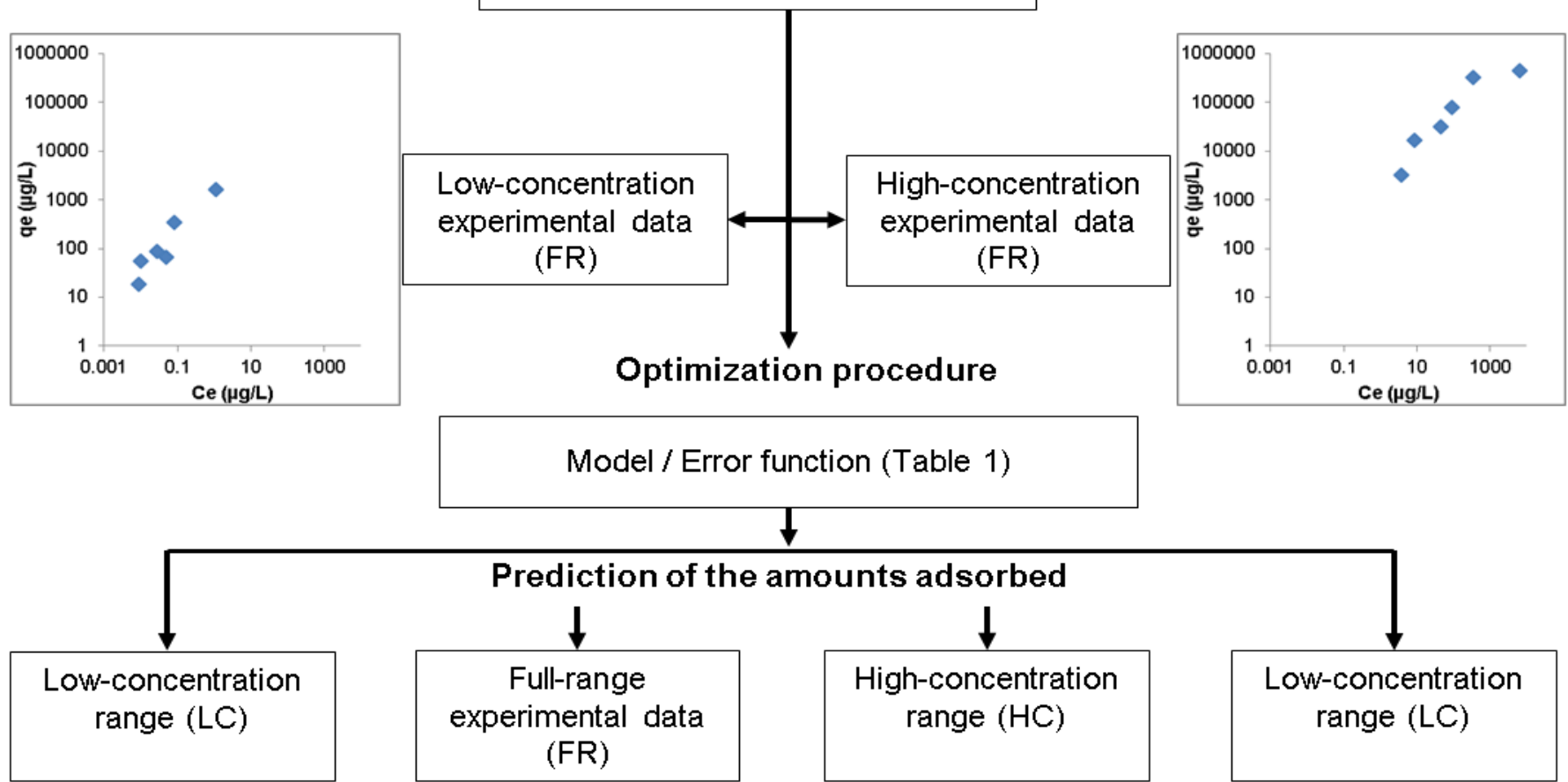

\section{Comparison with experimental data}
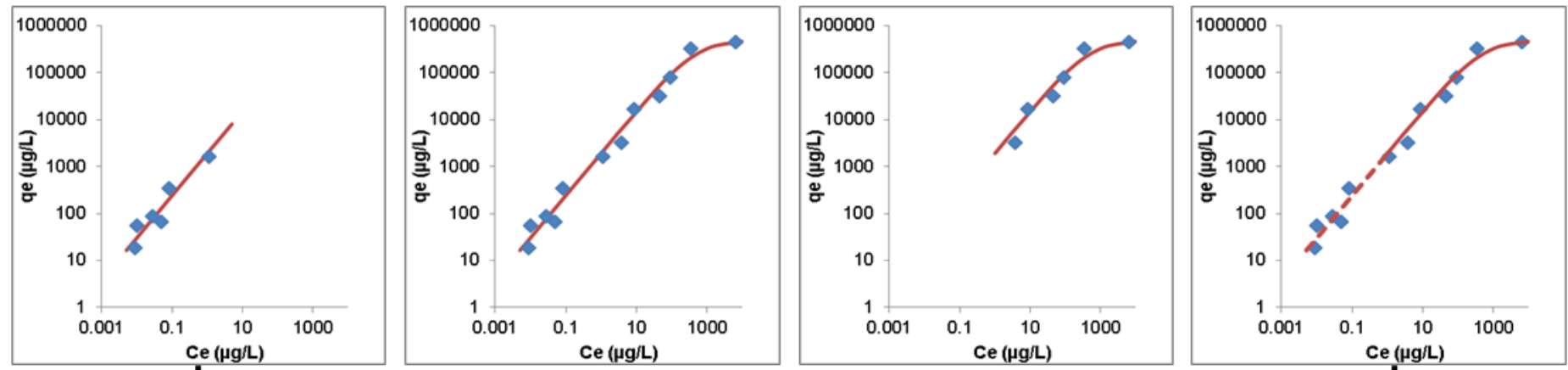

Figure 1. Methodology for the optimization procedure and the extrapolation of the model to the low-range concentrations 


\section{Results and discussion}

\subsection{Kinetics of adsorption}

Kinetic studies are essential to determine the contact time at which the adsorption equilibrium is reached. Moreover, the change in aqueous concentration against time was used to compute the mass transfer coefficients for each pollutant/adsorbent system. Assuming that the adsorbent particles are spherical and of unique size, (Matthews and Weber, 1977) proposed a kinetic model based on the fact that the overall adsorption is kinetically limited by external and diffusion steps. This homogeneous surface diffusion model (HSDM) supposes that the diffusion has two major limiting steps: diffusion through the external film surrounding the particle and surface diffusion inside the porosity. Thus, two coefficients were evaluated (i) Kf, which represents the external mass transfer, and (ii) Ds, which corresponds to the surface diffusivity. For each adsorbate/adsorbent couple studied, these two mass transfer coefficients were adjusted at high and low concentrations (Table 5) using an iterative optimization procedure (Traegner and Suidan, 1989). Figure $\mathbf{2}$ shows the kinetics of adsorption for two ranges of concentration, starting at $10 \mathrm{mg} \cdot \mathrm{L}^{-1}$ or $10 \mu \mathrm{g} \cdot \mathrm{L}^{-1}$. The equilibrium times were highly dependent on the initial concentration whereas the nature of the compounds did not influence the equilibration time. For the lowest concentration, a contact time of 10 days was required to reach equilibrium and this decreased to $50 \mathrm{~h}$ when the initial concentration was $10 \mathrm{mg} . \mathrm{L}^{-}$

\footnotetext{
1.
} 

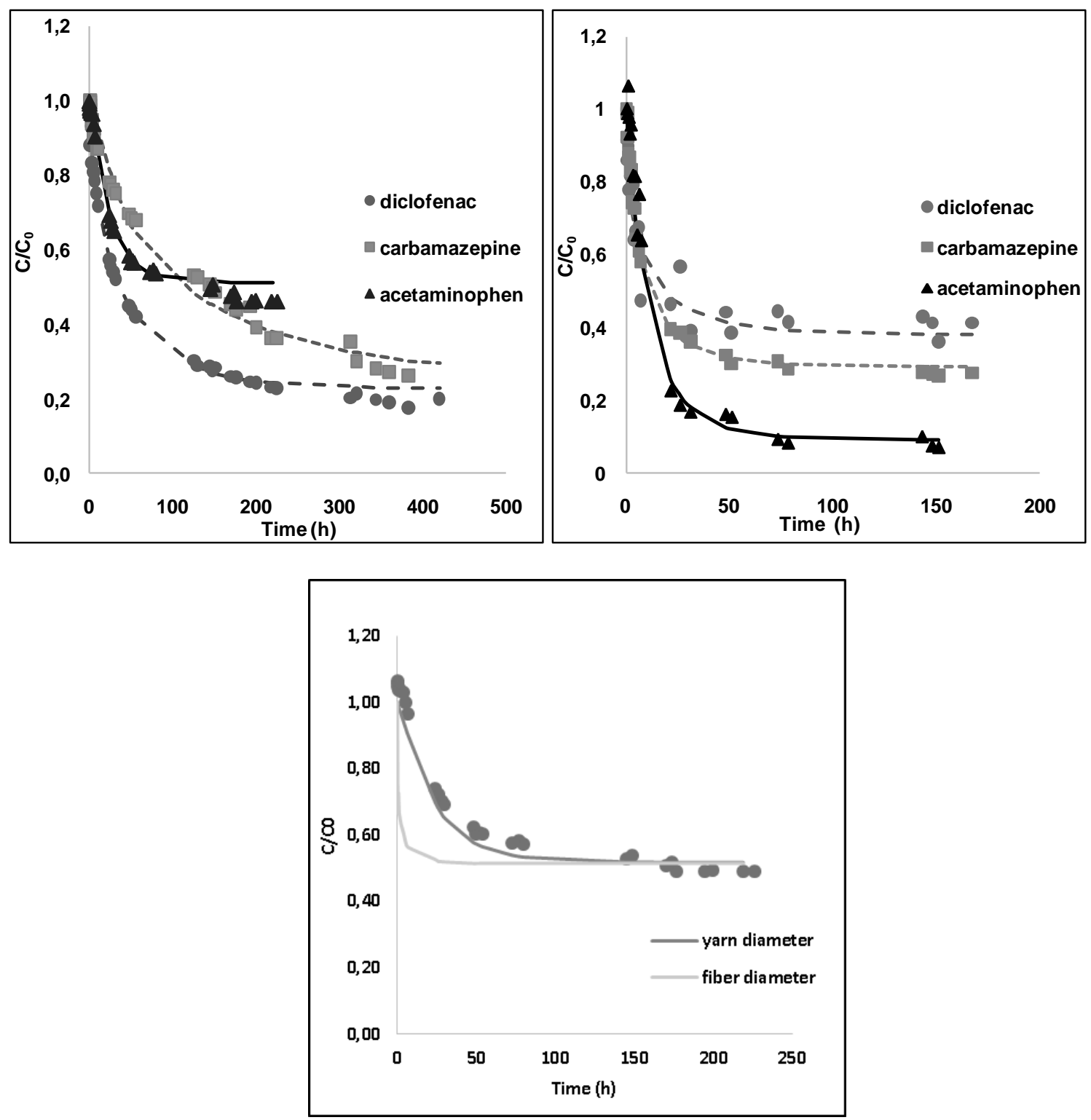

Figure 2. Kinetic curves of adsorption obtained at (a) high concentration $\left(C_{0}=10 \mathrm{mg} / \mathrm{L}\right)$ and (b) low concentration $\left(C_{0}=10 \mu \mathrm{g} / \mathrm{L}\right)$. Solid line corresponds to the HSDM model.

For conventional adsorbents, such as powders or grains of activated carbon, the average particle size is commonly determined by physical analysis (optical granulometry or sieving). However, these approaches are not relevant for ACFC, so the particle size was determined using image analysis by scanning electron microscopy. The images obtained show that ACFC KIP-1200 is constituted of 430$\mu \mathrm{m}$ yarns, which are themselves made of fibers (10- $\mu \mathrm{m}$ average diameter). As established by Mathews \& Weber (1977), the HSDM was not appropriate to take into account this dual geometry. Both scales, yarn and fiber, were considered for the adjustment of the mass transfer coefficients (Kf 
and Ds). Using the fiber diameter as the elementary particle size resulted in large differences between the modeled and experimental values. On the contrary, when considering the yarn diameter, the adjustment was relevant (Figure 2). Therefore, the external resistance to the mass transfer occurred in the film around the yarn while the flow between the fibers was neglected. Consequently, the adjusted Ds coefficients combined the diffusions inside the porosity and through the liquid film inside the yarn, between the fibers.

Table 5. Mass transfer coefficients at different intital concentrations $\left(C_{0}\right)$ of micropollutants

\begin{tabular}{|c|c|c|c|c|c|c|}
\hline & \multicolumn{3}{|c|}{$\mathrm{C}_{0}=10 \mathrm{mg} \cdot \mathrm{L}^{-1}$} & \multicolumn{3}{|c|}{$C_{0}=10 \mu \mathrm{g} \cdot \mathrm{L}^{-1}$} \\
\hline & Ds $\left(m^{2} \cdot s^{-1}\right)$ & $K f\left(m \cdot s^{-1}\right)$ & $\begin{array}{c}\text { Biot } \\
\text { number }\end{array}$ & Ds $\left(m^{2} \cdot s^{-1}\right)$ & $K f\left(m \cdot s^{-1}\right)$ & $\begin{array}{c}\text { Biot } \\
\text { number }\end{array}$ \\
\hline Diclofenac & $6.1 \times 10^{-14}$ & $2.0 \times 10^{-4}$ & 21.8 & $1.3 \times 10^{-13}$ & $2.8 \times 10^{-3}$ & 53.3 \\
\hline Acetaminophen & $2.1 \times 10^{-13}$ & $2.3 \times 10^{-5}$ & 2.5 & $1.2 \times 10^{-13}$ & $4.1 \times 10^{-4}$ & 1.5 \\
\hline Carbamazepine & $3.5 \times 10^{-14}$ & $1.3 \times 10^{-5}$ & 6.1 & $1.4 \times 10^{-13}$ & $7.4 \times 10^{-4}$ & 6.6 \\
\hline
\end{tabular}

In Table 5, the Biot numbers (ranging from 1.5 to 53.3) highlight the preponderance of both surface diffusion and external mass transfer as the limiting steps for mass transfer. The coefficients of external transfer, $\mathrm{Kf}$, described the diffusion molecules through the boundary layer around the yarn. Furthermore, these external coefficients were shown to be solely influenced by the range of concentration, and independent of the type of adsorbed compound. At the highest concentration, $\mathrm{Kf}$ ranged from $1.3 \times 10^{-5}$ to $2.0 \times 10^{-4} \mathrm{~m} \cdot \mathrm{s}^{-1}$. At trace concentrations, this coefficient increased to between $4.1 \times 10^{-4}$ and $2.8 \times 10^{-3} \mathrm{~m} \cdot \mathrm{s}^{-1}$.

Ds values, obtained at the high concentration, varied by three orders of magnitude, $3.1 \times 10^{-15} \mathrm{~m}^{2} \cdot \mathrm{s}^{-1}$, for diclofenac. In comparison, at the low concentration, the surface diffusivities were similar for all compounds and only varied by one order of magnitude, from $4.4 \times 10^{-14}$ to $1.4 \times 10^{-13} \mathrm{~m}^{2} . \mathrm{s}^{-1}$. For granular activated carbon, (Baup et al., 2000) have shown Ds coefficients equal to $10^{-14} \mathrm{~m}^{2} . \mathrm{s}^{-1}$, for an initial concentration of $0.5 \mu \mathrm{g} \cdot \mathrm{L}^{-1}$. (Al Mardini and Legube, 2009) have reported some coefficients of $10^{-16} \mathrm{~m}^{2} \cdot \mathrm{s}^{-1}$ for powdered activated carbon, with an initial concentration of $1 \mu \mathrm{g} \cdot \mathrm{L}^{-1}$. 
Two types of behavior were thus observed. On one hand, for carbamazepine, a significant decrease in Ds coefficients was seen as the bulk concentration decreased. On the other hand, no significant changes were observed for acetaminophen and diclofenac with the initial concentration. The steric effect could not explain these different behaviors. For instance, the molecular weight of diclofenac $\left(\mathrm{M}=318.1 \mathrm{~g} \cdot \mathrm{mol}^{-1}\right)$ is half that of acetaminophen $\left(\mathrm{M}=151.2 \mathrm{~g} \cdot \mathrm{mol}^{-1}\right)$ but these compounds exhibited similar surface diffusivities. Dipole moment, molecular volume or polarizability could explain these different behaviors.

\subsection{Modeling adsorption isotherms}

Isotherm curves of adsorption were obtained for each compound independently in ultra-pure water, without competition with organic matter. Every isotherm was modeled using the adsorption models mentioned in Table 3. The isotherm parameters were adjusted by minimizing the error functions (Table 3). Figure 3 presents the best "isotherm/error function" couple determined over the entire range of concentrations for each compound.
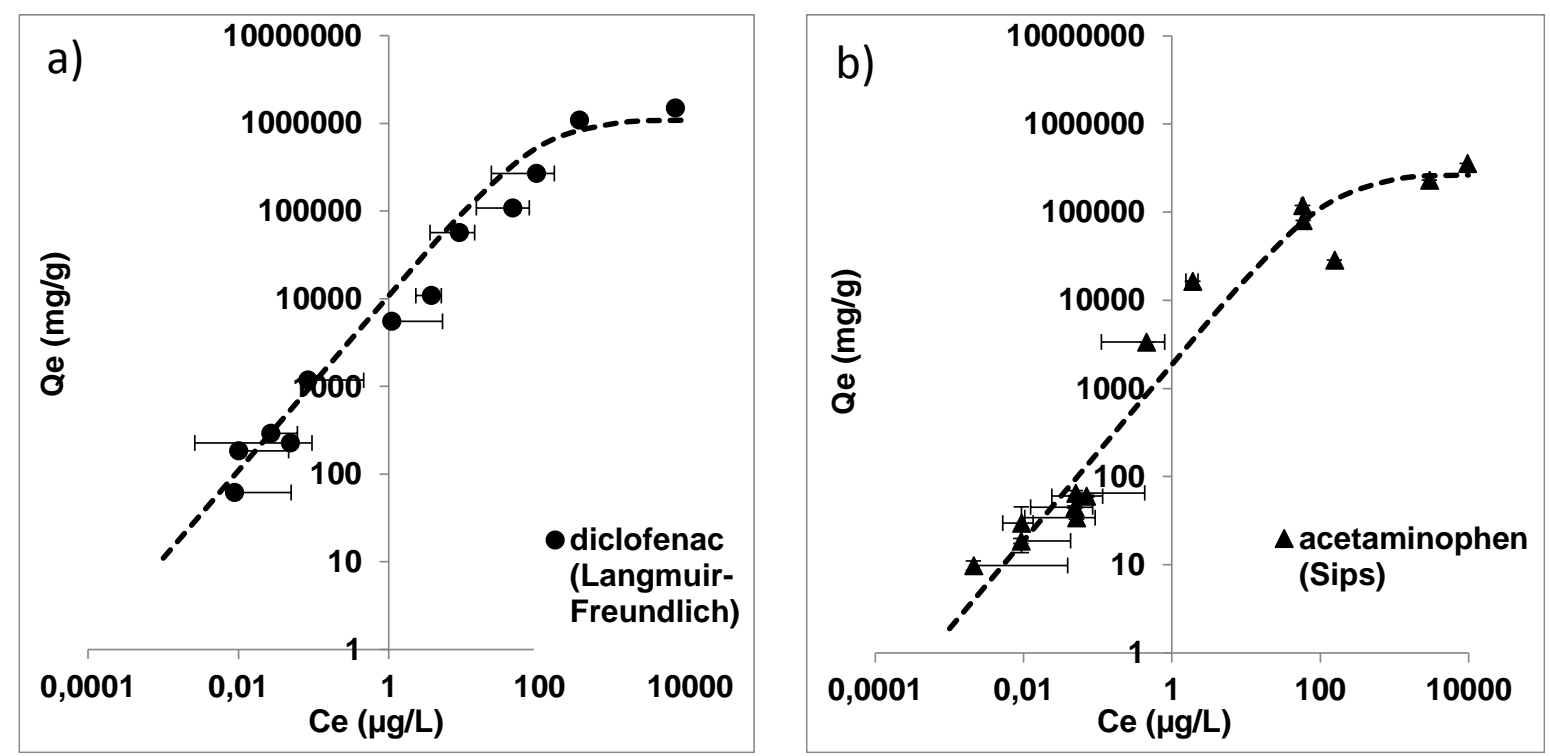


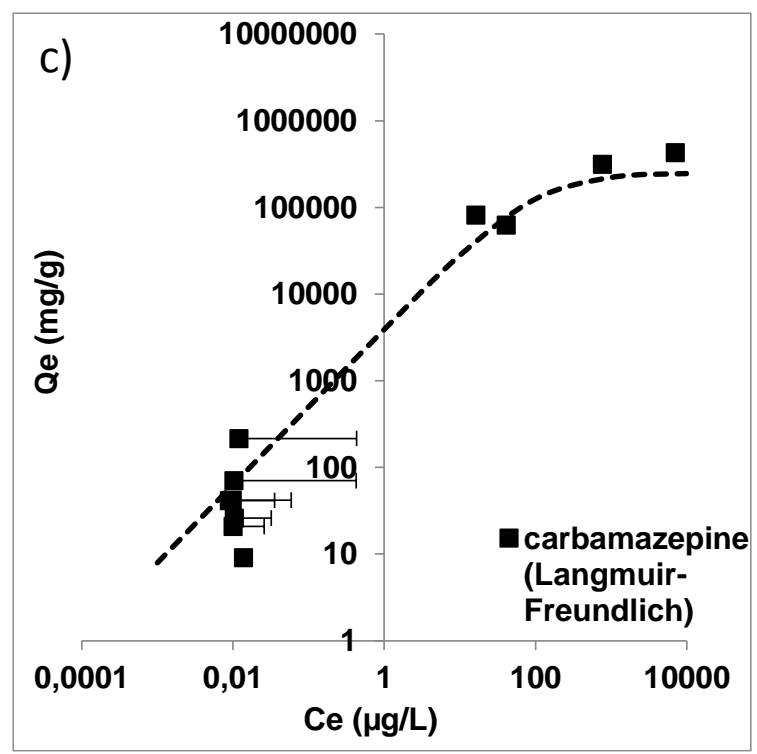

Figure 3. Adsorption isotherms of diclofenac, acetaminophen and carbamazepine on ACFC KIP-1200

In Figure 3, at the highest concentrations (above $10 \mathrm{ng} \cdot \mathrm{L}^{-1}$ ), the adsorption capacities were similar for all compounds (between 10 and $1000 \mu \mathrm{g} \cdot \mathrm{g}^{-1}$ ). On the contrary, when the concentration decreased, the adsorption capacities were significantly influenced by the nature of the adsorbed molecule. Likewise, different shapes of the adsorption isotherm curves were observed. The organic compounds had an "L-shape" isotherm. Each type of isotherm was related to different adsorption mechanisms. The concave "L-shape" isotherms were the most common. These experimental data were described by the Freundlich or the Langmuir model (Limousin et al., 2007).

For the highest concentrations, experimental errors were quite low. For instance, uncertainties were less than $5 \%$ for diclofenac. However, at the lowest concentrations, values were more dependent on the compound. For diclofenac, some experimental errors of $72 \%$ were observed, whereas for acetaminophen, they were only $20 \%$. An explication could come from the dispersion of points. For acetaminophen, values are relatively close to each other. On the contrary, for diclofenac, the dispersion is quite important.

The best descriptors for each adsorption isotherm are presented in Table 6. 
Table 6. Best descriptors for each adsorption isotherm equation

Full range of concentration

High range of concentration

\begin{tabular}{lcclc} 
Compound & \multicolumn{1}{c}{ Isotherm model } & Average $\mathbf{E}(\%)$ & Isotherm model & E (\%) \\
\hline Diclofenac & Langmuir-Freundlich/E & 55.5 & Toth/E & 13.9 \\
Carbamazepine & Langmuir-Freundlich/E & 42.4 & Elovich/MPSD & 17.3 \\
Acetaminophen & Sips/E & 40.9 & Elovich/E & 66.6
\end{tabular}

\subsection{Extrapolation of adsorption capacities}

The influences of the isotherm model, error function, and nature of the organic compound were significant with average relative errors $\mathrm{E}_{\mathrm{HC}-\mathrm{LC}}$ ranging from 60 to $10^{11} \%$. For extrapolation (using the procedure described in Figure 1) from high concentration parameters, relative errors were mostly over $100 \%$ for the three compounds (Figure 4).
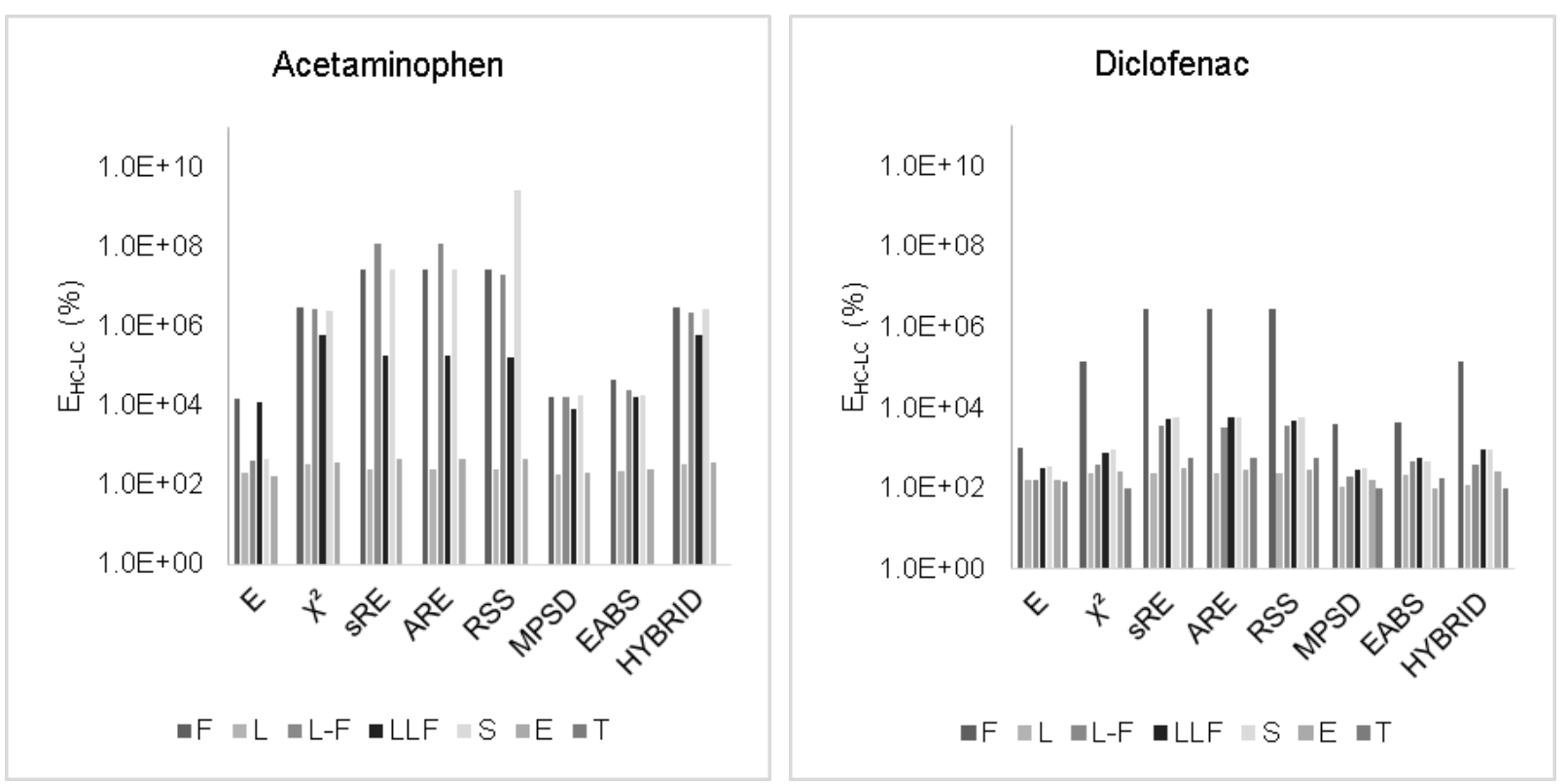


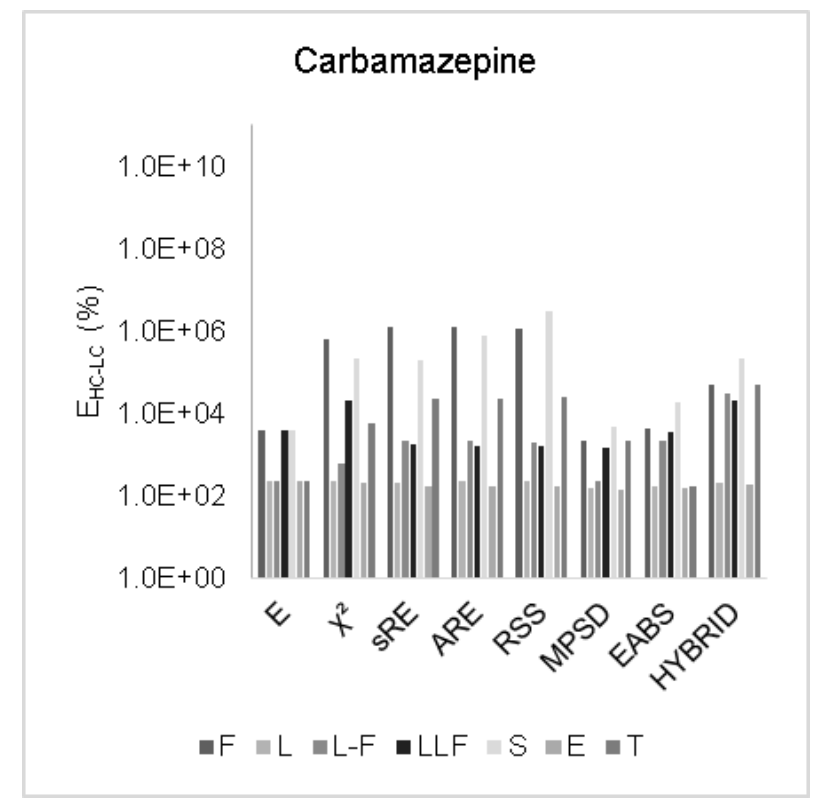

Figure 4. Extrapolation errors $\mathrm{E}_{\mathrm{HC}-\mathrm{LC}}$ from high concentration parameters (F: Freundlich; L: Langmuir; L-F: Langmuir-Freundlich; LLF: Linearized Langmuir-Freundlich; S: Sips; E: Elovich; T: Toth)

For diclofenac, the best extrapolations were obtained using the E error. Langmuir-Freundlich and Sips models led to the best extrapolation from high to low concentrations with $\mathrm{E}_{\mathrm{HC}-\mathrm{LC}}$ errors from 67 to $134 \%$, respectively. In a recent study, Nam et al. (2014) demonstrated that the Freundlich model was the most appropriate to describe the adsorption of diclofenac at low concentrations. For this study, the authors carried out diclofenac adsorption from 20 to $500 \mathrm{ng} \cdot \mathrm{L}^{-1}$, with powdered activated carbon $\left(1 \mathrm{mg} \cdot \mathrm{L}^{-1}\right)$. They showed that adsorption parameters were well adjusted by the Freundlich isotherm for hydrophobic compounds. However, in this study, Freundlich models, with all error functions, led to significant deviations in terms of the extrapolation. Errors were widely influenced by the high range of concentrations. The Freundlich isotherm can describe neither the linear range at very low concentrations nor the saturation effect at high concentrations (Worch, 2012).

Moreover, the linearized Langmuir-Freundlich model did not provide a better extrapolation than the non-linear Langmuir-Freundlich model. (Choi et al., 2006) have shown that linear models have a poor fit for hydrophobic compounds. This conclusion was thus confirmed. 
In the case of carbamazepine, Langmuir and Elovich models provided an acceptable extrapolation with an error of about $100 \%$. Moreover, the error function did not play a significant role in the accuracy of the extrapolation. On the contrary, the selected error function greatly influenced the accuracy of extrapolation when the Toth or Langmuir-Freundlich models were used. With these models, acceptable results were obtained with the E error (about $100 \%$ ) but revealed a large deviation (over $1000 \%$ ) when the hybrid error function was considered.

According to the results obtained for carbamazepine, the Freundlich model appeared to be the worst choice to predict adsorption capacities at trace concentration from values obtained at high concentrations. However, this model is not so inaccurate for fitting experimental data at high concentrations or for the full range of concentrations. Like for diclofenac, linearization of the Langmuir-Freundlich model did not improve its extrapolation ability.

Similar conclusions were obtained with acetaminophen. Langmuir and Elovich models led to the most accurate predictions irrespective of the error function. However, if all models are considered, E, MPSD and EABS errors gave the best extrapolations. Except for Langmuir and Elovich, RSS and ARE had errors of extrapolation higher than $10^{5} \%$. Unlike diclofenac and carbamazepine, the linearized Langmuir-Freundlich model gave the best extrapolation. This result is in agreement with Kumar et al. (2008) and Nam et al. (2014) who observed that acetaminophen could be fitted with precision by a linear isotherm.

For all organic compounds, for two-parameter isotherm models, E and MPSD functions were found to be a good option to minimize the error distribution between the experimental and predicted adsorption capacities. Kumar et al. (2008) obtained similar results for their predicted isotherms at high concentrations. Three-parameter models were not better than two-parameter models during extrapolation. This observation is not true for fitting; the addition of parameters decreased the error (Table 6). For three-parameter equations, E and EABS were found to be the best functions in minimizing the error distribution. More generally, for all studied molecules and isotherm models, the 
error function E was highlighted as the most relevant, although significant deviations were computed in some cases. If all molecules are considered, the Langmuir/MPSD, Elovich/E, Langmuir/E, Elovich/MPSD and Langmuir-Freundlich/E couples could be used to extrapolate the models to the lowest residual concentrations. These relationships were the most efficient. For instance, Elovich/E exhibited relative errors of $66 \%, 113 \%$ and $96 \%$ for acetaminophen, diclofenac and carbamazepine, respectively.

In order to extend the discussion, the errors of extrapolations from the high range of concentrations ( $\mathrm{E}_{\mathrm{HC}-\mathrm{LC}}$, previously shown in Figure 4) were compared to those determined for the full range of concentrations ( $\left.E_{F R-L C}\right)$. The results are presented in Figure 2. Thus, if the ratio $E_{H C-L C} / E_{F R-L C}$ approaches 1 , it means that there is no additional error caused by the extrapolation procedure and the model could be perfectly fitted at the highest concentrations and then extrapolated to the lowest concentrations. In these cases, the determination of isotherm parameters based only on the high concentration is relevant to predict equilibrium at trace concentration. 


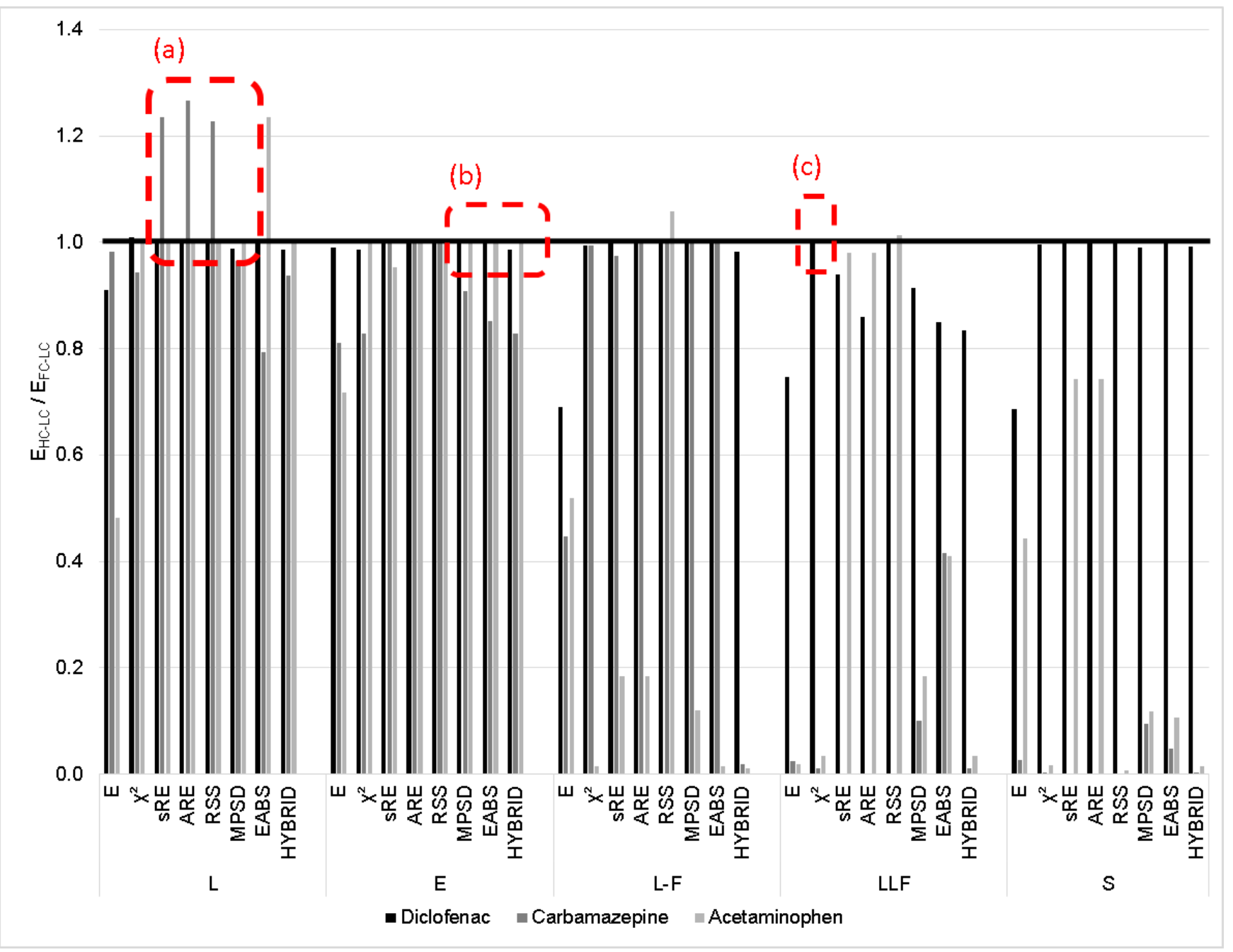

Figure 5. Evolution of the error function calculated from extrapolation of adsorption curves at high and full range of concentrations

In Figure 5, three zones are highlighted ( $a, b$ and $c)$, which show the best "model/error function" combinations for all organic molecules. For these couples, the ratio of errors was close to 1 , meaning that no additional error was added by the extrapolation from high concentrations. Namely, the Langmuir equation could be associated with the $S_{R E}$ ARE, RSS and MPSD error functions, the Elovich equation with $\mathrm{SRE}_{\mathrm{RE}}$ ARE, RSS and MPSD and the Langmuir-Freundlich model with RSS.

It should be noted that, from Figure 4, the Langmuir/MPSD, Elovich/E, Langmuir/E, Elovich/MPSD and Langmuir-Freundlich/E couples were highlighted for their absolute accuracy of extrapolation. 
Therefore, considering the results presented in Figure 5, it was concluded that, for all organic compounds, the Langmuir/MPSD couple was the best choice for extrapolation. In fact, the extrapolation error was among the smallest and extrapolation from the high concentrations did not add significant errors compared to the adjustment over the entire range of concentrations.

Table 7. Isotherm parameters for the best model

\begin{tabular}{ll|cccc|cccc|ccc}
\hline Compound & Isotherm & \multicolumn{3}{c}{$\begin{array}{c}\text { Full range of } \\
\text { concentration }\end{array}$} & \multicolumn{3}{c}{$\begin{array}{c}\text { High range of } \\
\text { concentration }\end{array}$} & \multicolumn{3}{c}{$\begin{array}{c}\text { Low range of } \\
\text { concentration }\end{array}$} \\
\hline Dodel & Langmuir- & $\mathrm{q}_{\mathrm{m}}$ & $\mathrm{b}$ & $\mathrm{n}$ & $\mathrm{q}_{\mathrm{m}}$ & $\mathrm{b}$ & $\mathrm{n}$ & $\mathrm{q}_{\mathrm{m}}$ & $\mathrm{b}$ & $\mathrm{n}$ \\
& Freundlich/E & 1525.8 & 1.0 & 1.3 & 1611 & 0.7 & 1.1 & 1670.4 & 16.8 & 2.1 \\
Carbamazepine & Langmuir- & $\mathrm{q}_{\mathrm{m}}$ & $\mathrm{b}$ & $\mathrm{n}$ & $\mathrm{q}_{\mathrm{m}}$ & $\mathrm{b}$ & $\mathrm{n}$ & $\mathrm{q}_{\mathrm{m}}$ & $\mathrm{b}$ & $\mathrm{n}$ \\
& Freundlich/E & 521.1 & 0.1 & 0.7 & 568.1 & 2.3 & 0.9 & 1954.9 & 0.6 & 0.9 \\
Acetaminophen & Sips/E & $\mathrm{q}_{\mathrm{m}}$ & $\mathrm{b}$ & $\mathrm{n}$ & $\mathrm{q}_{\mathrm{m}}$ & $\mathrm{b}$ & $\mathrm{n}$ & $\mathrm{q}_{\mathrm{m}}$ & $\mathrm{b}$ & $\mathrm{n}$ \\
& & 4149.1 & 0.1 & 0.8 & 2893.9 & 0.1 & 0.9 & 165.0 & 0.1 & 0.5 \\
\hline
\end{tabular}

Units are based on liquid-phase concentration expressed in $\mu \mathrm{g} \cdot \mathrm{L}^{-1}$ and amounts adsorbed in $\mu \mathrm{g} \cdot \mathrm{g}^{-1}$

As shown in Table 7, isotherm parameters have different behaviors according to the compound and range of concentration. The " $n$ " parameter is little impacted by the extrapolation of adsorption capacities from high to low concentrations. Except for diclofenac, the change in concentration has no influence on the " $b$ " parameter.

For diclofenac, which presents the lowest extrapolation errors, the $q_{m}$ coefficients are not impacted by extrapolation. For the other compounds, this parameter is influenced by the range of concentration.

\section{Conclusion}

In this study, we investigated the sorption of three pharmaceutical compounds onto activated carbon fiber cloth. Adsorption kinetic coefficients were little impacted by the initial concentration for 
diclofenac and acetaminophen. For a residual concentration of $0.1 \mu \mathrm{g} \cdot \mathrm{L}^{-1}$, adsorption capacities were 116, 134 and $248 \mu \mathrm{g} \cdot \mathrm{g}^{-1}$ for diclofenac, acetaminophen and carbamazepine, respectively.

The ability of several isotherm models associated with different error functions to extrapolate adsorption capacities from high to low concentrations was evaluated.

Among the 104 combinations, for diclofenac, carbamazepine and acetaminophen, which present the usual isotherm shape, the Langmuir-Freundlich model adjusted with the MPSD error enabled the best extrapolation from $\mathrm{mg} \cdot \mathrm{L}^{-1}$ to $\mu \mathrm{g} \cdot \mathrm{L}^{-1}$.

\section{Acknowledgments}

The authors gratefully acknowledge the French National Research Agency for funding this research work. 
References

Allen, S.J., Gan, Q., Matthews, R., Johnson, P.A., 2003. Comparison of optimised isotherm models for basic dye adsorption by kudzu. Bioresour. Technol. 88, 143-152. doi:10.1016/S09608524(02)00281-X

Al Mardini, F., Legube, B., 2010. Effect of the adsorbate (Bromacil) equilibrium concentration in water on its adsorption on powdered activated carbon. Part 3: Competition with natural organic matter. J. Hazard. Mater. 182, 10-17. doi:10.1016/j.jhazmat.2010.05.035

Al Mardini, F., Legube, B., 2009. Effect of the adsorbate (Bromacil) equilibrium concentration in water on its adsorption on powdered activated carbon. Part 1. Equilibrium parameters. J. Hazard. Mater. 170, 744-753. doi:10.1016/j.jhazmat.2009.05.003

Assoumani, A., Favier-Teodorescu, L., Wolbert, D., 2009. Adsorptiion kinetics and isotherm characteristics of selected endocrine disrupting compounds on activated carbon in natural waters. Water Sci. Technol. 9, 51-58.

Ayoob, S., Gupta, A.K., 2008. Insights into isotherm making in the sorptive removal of fluoride from drinking water. J. Hazard. Mater. 152, 976-985. doi:10.1016/j.jhazmat.2007.07.072

Ayranci, E., Duman, O., 2006. Adsorption of aromatic organic acids onto high area activated carbon cloth in relation to wastewater purification. J. Hazard. Mater. 136, 542-552.

Ayranci, E., Hoda, N., 2005. Adsorption kinetics and isotherms of pesticides onto activated carboncloth. Chemosphere 60, 1600-1607.

Baup, S., Jaffre, C., Wolbert, D., Laplanche, A., 2000. Adsorption of pesticides onto granular activated carbon : Determination of surface diffusivities using simple batch experiments. Adsorption 6 , 219-228.

Bayram, E., Ayranci, E., 2012. Electrosorption based waste water treatment system using activated carbon cloth electrode: Electrosorption of benzoic acid from a flow-through electrolytic cell. Sep. Purif. Technol. 86, 113-118.

Boehm, H.P., 1994. Some aspects of the surface chemistry of carbon blacks and other carbons. Carbon 32, 759-769. doi:10.1016/0008-6223(94)90031-0

Boulinguiez, B., Le Cloirec, P., Wolbert, D., 2008. Revisiting the determination of langmuir parameters--application to tetrahydrothiophene adsorption onto activated carbon. Langmuir ACS J. Surf. Colloids 24, 6420-6424. doi:10.1021/la800725s

Brasquet, C., Roussy, J., Subrenat, E., Le Cloirec, P., 1996. Adsorption and selectivity of activated carbon fibers application to organics. Environ. Technol. 17, 1245-1252.

Cai, N., Larese-Casanova, P., 2014. Sorption of carbamazepine by commercial graphene oxides: a comparative study with granular activated carbon and multiwalled carbon nanotubes. J. Colloid Interface Sci. 426, 152-161.

Chan, L.S., Cheung, W.H., Allen, S.J., McKay, G., 2012. Error Analysis of Adsorption Isotherm Models for Acid Dyes onto Bamboo Derived Activated Carbon. Chin. J. Chem. Eng. 20, 535-542. doi:10.1016/S1004-9541(11)60216-4

Chen, H., Zha, J., Liang, X., Li, J., Wang, Z., 2014. Effects of the human antiepileptic drug carbamazepine on the behavior, biomarkers, and heat shock proteins in the Asian clam Corbicula fluminea. Aquat. Toxicol. 155, 1-8.

Choi, K.J., Kim, S.G., Kim, C.W., Park, J.K., 2006. Removal efficiencies of endocrine disrupting chemicals by coagulation/flocculation, ozonation, powdered/granular activated carbon adsorption, and chlorination. Korean J. Chem. Eng. 23, 399-408. doi:10.1007/BF02706741

Condon, J., 2006. Surface area and porosity determinations by physisorption: measurements and theory. Elsevier, The Netherlands.

Dabrowski, A., Podkoscielny, P., Hubicki, Z., Barczak, M., 2005. Adsorption of phenolic compounds by activated carbon-a critical review. Chemosphere 58, 1049-1070. 
Das, L., Barodia, S.K., Sengupta, S., Basu, J.K., 2014. Aqueous degradation kinetics of pharmaceutical drug diclofenac by photocatalysis using nanostructured titania-zirconia composite catalyst. Int. J. Environ. Sci. Technol. 12, 317-326.

De Jesus Gaffney, V., Almeida, C.M., Rodrigues, A., Ferreira, E., Benoliel, M.J., Cardoso, V.V., 2015. Occurrence of pharmaceuticals in a water supply system and related human health risk assessment. Water Res. 72, 199-208.

Elovich, S.Y., Larinov, O.G., 1962. Theory of adsorption from solutions of non electrolytes on solid (I) equation adsorption from solutions and the analysis of its simplest form,(II) verification of the equation of adsorption isotherm from solutions. Izv Akad Nauk SSSR Otd Khim Nauk 2, 209-216.

Faur-Brasquet, C., Métivier-Pignon, H., Le Cloirec, P., 2002. Activated carbon cloths in water and wastewater treatments. Res Adv Water Res. 2.

Foo, K.Y., Hameed, B.H., 2010. Insights into the modeling of adsorption isotherm systems. Chem. Eng. J. 156, 2-10.

Foo, K.Y., Hameed, B.H., 2009. A short review of activated carbon assisted electrosorption process: An overview, current stage and future prospects. J. Hazard. Mater. 170, 552-559. doi:10.1016/j.jhazmat.2009.05.057

Freundlich, H., 1906. Über die adsorption in lösungen. Z. Für Phys.

Gamarra, J.S., Locateli Godoi, A.F., Carvalho de Vasconcelos, E., Tavares de Souza, K.M., Ribas de Oliveira, C.M., 2015. Environmental risk assessment (ERA) of diclofenac and ibuprofen : a public health perspective. Chemosphere 120, 462-469. doi:10.1016/j.chemosphere.2014.08.020

Guedidi, H., Reinert, L., Soneda, Y., Bellakhal, N., Duclaux, L., 2014. Adsorption of ibuprofen from aqueous solution on chemically surface-modified activated carbon cloths. Arab. J. Chem. doi:10.1016/j.arabjc.2014.03.007

Ho, Y.-S., 2004. Selection of optimum sorption isotherm. Carbon 42, 2115-2116. doi:10.1016/j.carbon.2004.03.019

Huerta-Fontela, M., Galceran, M.T., Ventura, F., 2011. Occurrence and removal of pharmaceuticals and hormones through drinking water treatment. Water Res. 45, 1432-1442. doi:10.1016/j.watres.2010.10.036

Jumasiah, A., Chuah, T.G., Gimbon, J., Choong, T.S.Y., Azni, I., 2005. Adsorption of basic dye onto palm kernel shell activated carbon: sorption equilibrium and kinetics studies. Desalination 186, 57-64. doi:10.1016/j.desal.2005.05.015

Kapoor, A., Yang, R.T., 1989. Correlation of equilibrium adsorption data of condensible vapours on porous adsorbents. Gas Sep. Purif. 3, 187-192. doi:10.1016/0950-4214(89)80004-0

Kumar, K.V., 2006. Linear and non-linear regression analysis for the sorption kinetics of methylene blue onto activated carbon. J. Hazard. Mater. 137, 1538-1544. doi:10.1016/j.jhazmat.2006.04.036

Kumar, K.V., Porkodi, K., Rocha, F., 2008a. Isotherms and thermodynamics by linear and non-linear regression analysis for the sorption of methylene blue onto activated carbon: Comparison of various error functions. J. Hazard. Mater. 151, 794-804. doi:10.1016/j.jhazmat.2007.06.056

Kumar, K.V., Porkodi, K., Rocha, F., 2008b. Comparison of various error functions in predicting the optimum isotherm by linear and non-linear regression analysis for the sorption of basic red 9 by activated carbon. J. Hazard. Mater. 150, 158-165. doi:10.1016/j.jhazmat.2007.09.020

Kummerová, M., Zezulka, Š., Babula, P., Tříska, J., 2015. Possible ecological risk of two pharmaceuticals diclofenac and paracetamol demonstrated on a model plant Lemna minor. J. Hazard. Mater. in Press. doi:10.1016/j.jhazmat.2015.09.057

Langmuir, I., 1915. Modelisation of adsorption. Phys Rev 6, 79-80.

Limousin, G., Gaudet, J.-P., Charlet, L., Szenknect, S., Barthès, V., Krimissa, M., 2007. Sorption isotherms: A review on physical bases, modeling and measurement. Appl. Geochem. 22, 249-275. doi:10.1016/j.apgeochem.2006.09.010 
Loos, R., Gawlik, B., Locoro, G., Rimaviciute, E., Contini, S., Bidoglio, G., 2009. EU-wide survey of polar organic persistent pollutants in European river waters. Environ. Pollut. 157, 561-568. doi:10.1016/j.envpol.2008.09.020

Lopez-Ramon, M.V., Stoeckli, F., Moreno-Castilla, C., Carrasco-Marin, F., 1999. On the characterization of acidic and basic surface sites on carbons by various techniques. Carbon $37,1215-1221$.

Marquardt, D., 1963. An Algorithm for Least-Squares Estimation of Nonlinear Parameters. J. Soc. Ind. Appl. Math. 11, 431-441. doi:10.1137/0111030

Matsui, Y., Fukuda, Y., Inoue, T., Matsushita, T., 2003. Effect of natural organic matter on powdered activated carbon adsorption of trace contaminants: characteristics and mechanism of competitive adsorption. Water Res. 37, 4413-4424. doi:10.1016/S0043-1354(03)00423-8

Matthews, A.P., Weber, W.J., 1977. Effects of external mass transfer and intraparticle diffusion on adsorption rates in slurry reactors. AlChE Symp Ser 73, 91-98.

Nam, S.-W., Choi, D.-J., Kim, S.-K., Her, N., Zoh, K.-D., 2014. Adsorption characteristics of selected hydrophilic and hydrophobic micropollutants in water using activated carbon. J. Hazard. Mater. 270, 144-152. doi:10.1016/j.jhazmat.2014.01.037

Ng, J.C.Y., Cheung, W.H., McKay, G., 2003. Equilibrium studies for the sorption of lead from effluents using chitosan. Chemosphere 52, 1021-1030. doi:10.1016/S0045-6535(03)00223-6

Petrie, B., Barden, R., Kaspryk-Hordern, B., 2014. A review on emerging contaminants in wastewaters and the environment : Current knowledge, understudied areas and recommendations for future monitoring. Water Res. In Press, Corrected Proof.

Rigobello, E.S., Dantas, A.D., Di Bernardo, L., Vieira, E.M., 2013. Removal of diclofenac by conventional drinking water treatment processes and granular activated carbon filtration. Chemosphere 92, 184-191. doi:10.1016/j.chemosphere.2013.03.010

Rouquerol, F., Rouquerol, J., Sing, K., 1999. Adsorption by powders and porous solids : principles, methodology and applications, Academic Press. ed. Londres.

Rouquerol, J., Avnir, D., Everett, D.H., Fairbridge, C., Haynes, M., Pernicone, N., Ramsay, J.D.F., Sing, K.S.W., Unger, K.K., 1994. Guidelines for the Characterization of Porous Solids. Stud. Surf. Sci. Catal., Characterization of Porous Solids III 87, 1-9. doi:10.1016/S0167-2991 (08)63059-1

Ruthven, D.M., 1984. Principles of adsorption and adsorption processes. John Wiley \& Sons.

Segura, P.A., MacLeod, S.L., Lemoine, P., Sauvé, S., Gagnon, C., 2011. Quantification of carbamazepinr and atrazine and screening of suspect orgnaic contaminants in surface and drinking water. Chemosphere 84, 1085-1094. doi:10.1016/j.chemosphere.2011.04.056

Sips, R., 1948. On the structure of a catalyst surface. J. Chem. Phys. 16, 490-495.

Sotelo, J.L., Ovejero, G., Rodriguez, A., Alvarez, S., Galan, J., Garcia, J., 2014. Competitive adsorption studies of caffeine and diclofenac aqueous solutions by activated carbon. Chem. Eng. J. 240, 443-453.

Toth, J., 1971. State equations of the solid gas interface layer. Acta Chem Acad Hung 69, 311-317.

Traegner, U.K., Suidan, M.T., 1989. Evaluation of surface and film diffusion coefficients for carbon adsorption. Water Res. 23, 267-273. doi:10.1016/0043-1354(89)90091-2

Webb, S., Ternes, T., Gibert, M., Olejniczak, K., 2003. Indirect human exposure to pharmaceuticals via drinking water. Toxicol. Lett., Hot Spot Pollutants: Pharmaceuticals in the Environment 142, 157-167. doi:10.1016/S0378-4274(03)00071-7

Worch, E., 2012. Adsorption technology in water treatment.Fundamentals, processes, and modeling, De Gruyter. ed. Germany.

Yu, Z., Peldszus, S., Huck, P.M., 2008. Adsorption characteristics of selected pharmaceuticals and an endocrine disrupting compound-Naproxen, carbamazepine and nonylphenol-on activated carbon. Water Res. 42, 2873-2882. doi:10.1016/j.watres.2008.02.020 


\section{List of tables and figures}

Table 1 : Properties of pharmaceutical residues used in adsorption procedures

Table 2 : Physical and chemical properties of the ACFC

Table 3. Adsorption models and error functions for the adjustment of the isotherm adsorption model Table 4. Some uses of isotherm adsorption models with different error functions

Table 5. Mass transfer coefficients at different intital concentrations $\left(C_{0}\right)$ of micropollutants

Table 6. Best descriptors for each adsorption isotherm equation

Table 7. Isotherm parameters for the best model

Figure 1. Methodology for the optimization procedure and the extrapolation of the model to the lowrange concentrations

Figure 2. Kinetic curves of adsorption obtained at (a) high concentration $\left(C_{0}=10 \mathrm{mg} / \mathrm{L}\right)$ and (b) low concentration $\left(C_{0}=10 \mu \mathrm{g} / \mathrm{L}\right)$. Solid line corresponds to the HSDM model.

Figure 3. Adsorption isotherms of diclofenac, acetaminophen and carbamazepine on ACFC KIP-1200 Figure 4. Extrapolation errors $E_{\mathrm{HC}-\mathrm{LC}}$ from high concentration parameters (F: Freundlich; L: Langmuir; L-F: Langmuir-Freundlich; LLF: Linearized Langmuir-Freundlich; S: Sips; E: Elovich; T: Toth)

Figure 5. Evolution of the error function calculated from extrapolation of adsorption curves at high and full range of concentrations 